\title{
Effect of Geometrical Parameters on Wrinkling of 0Cr21Ni6Mn9N Stainless Steel Tube in Numerical Control Bending
}

\author{
Jun Fang ${ }^{1,2, a^{*}}$, Shiqiang Lu $^{2, b}$, Kelu Wang ${ }^{2, c}$ and Xuguang Min ${ }^{1}$ \\ 1Jiangxi Key Laboratory of Surface Engineering, Jiangxi Science and Technology Normal University, \\ Nanchang 330013, China \\ ${ }^{2}$ National Defense Key Discipline Laboratory of Light Alloy Processing Science and Technology, \\ Nanchang Hangkong University, Nanchang 330063, China \\ afangjun020j13@163.com, bniatlusq@126.com, cwangkelu@126.com
}

Keywords: $0 \mathrm{Cr} 21 \mathrm{Ni6Mn9N}$ tube, wrinkling, geometrical parameters, rotary draw bending

\begin{abstract}
In order to study the effects of geometrical parameters on wrinkling of $0 \mathrm{Cr} 21 \mathrm{Ni6} \mathrm{Mn} 9 \mathrm{~N}$ stainless steel tube in numerical control (NC) bending process, a three dimensional elastic plastic finite element model of the $0 \mathrm{Cr} 21 \mathrm{Ni} 6 \mathrm{Mn} 9 \mathrm{~N}$ stainless steel tube in $\mathrm{NC}$ bending was established based on ABAQUS/Explicit code, and its reliability was validated by experiment. Then, simulation and analysis of the effect rules of the bending angle, relative bending radius and relative tube diameter on wrinkling wave ratio were carried out. The results show that the wrinkling wave ratio increases with the increasing of the bending angle, and the amplitude of the increase slows down. The wrinkling wave ratio decreases with the increasing of the relative bending radius or decreasing of the relative tube diameter. The research results provide beneficial knowledge on bending behaviors of $0 \mathrm{Cr} 21 \mathrm{Ni} 6 \mathrm{Mn} 9 \mathrm{~N}$ stainless steel tube under different geometrical parameters and help efficient design and optimization of the forming parameters.
\end{abstract}

\section{Introduction}

Due to high strength, corrosion resistance and oxidation resistance, the $0 \mathrm{Cr} 21 \mathrm{Ni6Mn} 9 \mathrm{~N}$ stainless steel bent tube currently has attracted increasing applications in hydraulic, fuel systems for advanced aircraft and spacecraft as bleeding components [1]. Among various bending methods such as push bending, compress bending, stretch bending and roll bending, the numerical control (NC) bending is the most universal approach to achieve the qualified bent tubes due to high precision, high efficiency and digital advantages [2]. However, under multi-die constrains, the tube NC bending is a complex physical process with multiple influential factors and defects. As one of the most important forming defects in tube $\mathrm{NC}$ bending, the wrinkling has a significant influence on forming quality and precision and life of dies. Many different diameters, bending radii and angles of tubes have been used in various fields for different purposes. The wrinkling tendency changes with different specifications of tubes. Thus, it is useful to research the characteristics of wrinkling with the change of the geometrical parameters.

In recent years, great efforts have been conducted on the wrinkling of different kinds of tubular materials on bending processing using analytical, experimental or finite element (FE) simulation methods. Zhao et al.[3] proposed a wrinkling wave function and developed wrinkling prediction model in rotary draw bending of aluminum alloy thin-walled rectangular tube using plastic deformation theory combined with energy method, and the effects of materials parameters on wrinkling limit were studied. Peek [4] predicted the wrinkling in pure bending of aluminum alloy 
tube by finite strain three dimensional continuum theory. Corona et al.[5] experimentally investigated the effect of yield anisotropy on buckling of circular tube in bending process. By FE analysis, Chen et al.[6] studied the effect of processing parameters on wrinkling of thin-walled circular tube under rotary draw bending. Fang et al.[7] numerically researched the effects of friction between tube and die on wrinkling instability of the $0 \mathrm{Cr} 21 \mathrm{Ni} 6 \mathrm{Mn} 9 \mathrm{~N}$ stainless steel tube in NC bending. Li et al.[8] addressed the wrinkling characteristics and the effect of processing parameters on wrinkling of thin-walled tube NC bending combining the energy-based wrinkling prediction and FE simulation. The above publications mainly focused on the effects of the processing parameters or materials parameters on wrinkling in tube bending process. However, the study on wrinkling instability of the $0 \mathrm{Cr} 21 \mathrm{Ni} 6 \mathrm{Mn} 9 \mathrm{~N}$ stainless steel tube under different geometrical parameters in NC bending has not been reported. Therefore, Taking the $0 \mathrm{Cr} 21 \mathrm{Ni} 6 \mathrm{Mn} 9 \mathrm{~N}$ stainless steel tube of 15.88 $\times 0.84 \mathrm{~mm}$ (diameter $\times$ wall thickness)as the objective, a three dimensional (3D) elastic plastic FE model of tube NC bending is established based on ABAQUS/Explicit code, and then the effect rules of geometrical parameters on wrinkling instability of the $0 \mathrm{Cr} 21 \mathrm{Ni} 6 \mathrm{Mn} 9 \mathrm{~N}$ stainless steel tube during $\mathrm{NC}$ bending are studied by FE simulation.

\section{Description of wrinkling wave ratio}

The wrinkling instability can be qualitatively described by the wrinkling wave ratio $\eta$ as Eq.(1), the larger the $\eta$, the more serious the wrinkling tendency.

$$
\eta=\frac{D_{1}-D_{2}}{2 D} \times 100 \%
$$

Where $D_{1}, D_{2}$ is the maximum or minimum section length between the wave crest of the intrados and extrados of tube, respectively, $D$ is the initial tube outer diameter, as shown in Fig.1.

\section{FE model of tube NC bending and experimental validation}

According to the actual deformation of tube $\mathrm{NC}$ bending, a three dimensional (3D) elastic plastic FE model of the $0 \mathrm{Cr} 21 \mathrm{Ni} 6 \mathrm{Mn} 9 \mathrm{~N}$ stainless steel tube in $\mathrm{NC}$ bending is established based on ABAQUS/Explicit code, as shown in Fig.2. The detailed solutions involved in FE modeling can be found in literature [9], and the forming parameters of the $0 \mathrm{Cr} 21 \mathrm{Ni} 6 \mathrm{Mn} 9 \mathrm{~N}$ stainless steel tube NC bending in the paper are the same as literature [9].

Fig. 3 shows the comparison between experimental and simulative results of the wall thinning degree. It is found that the simulative results have a good agreement with the experimental ones, and the relative error between experiment and simulation results is less than $4 \%$. Thus, the FE model is reliable and can be used to explore the wrinkling characteristics in tube NC bending with the geometrical parameters change.

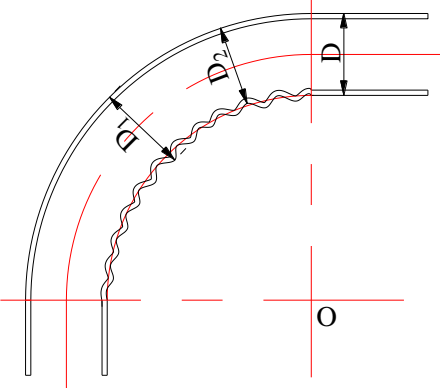

Fig.1 Schematic of wrinkling measurement

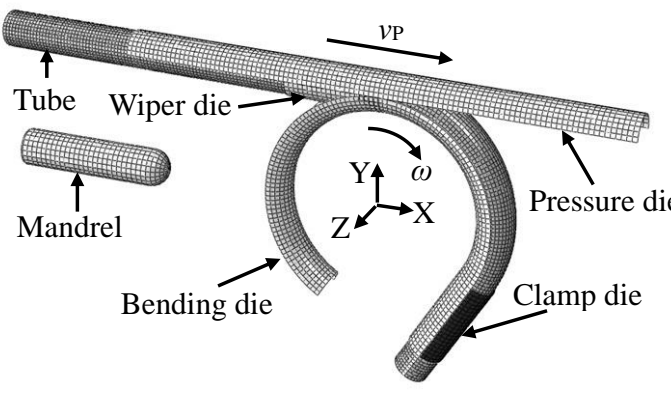

Fig.2 FE model of $0 \mathrm{Cr} 21 \mathrm{Ni} 6 \mathrm{Mn} 9 \mathrm{~N}$ tube in NC bending

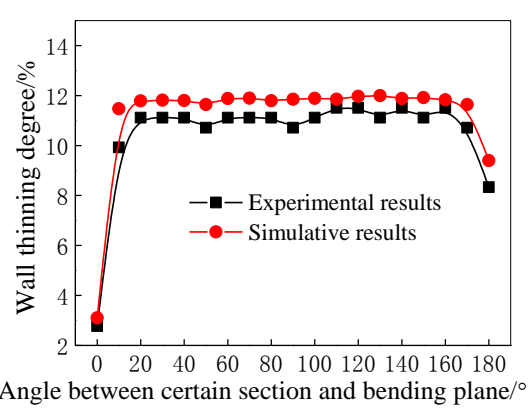

Fig.3 Comparison between experimental and simulative results 


\section{Effect of geometrical parameters on winkling in tube $\mathrm{NC}$ bending}

The geometrical parameters mainly includes bending angle $\theta$, relative bending radius $R / D$ and relative tube diameter $D / t$ ( $R, t$ denotes bending radius, wall thickness, respectively), which determine the deformation degree of bent tube. Thus, the effect rules of $\theta, R / D$ and $D / t$ on wrinkling in the $0 \mathrm{Cr} 21 \mathrm{Ni} 6 \mathrm{Mn} 9 \mathrm{~N}$ stainless steel tube NC bending are studied.

\subsection{Effect of bending angle on wrinkling.}

Fig.4(a) shows the effect of bending angle on wrinkling wave ratio of the $0 \mathrm{Cr} 21 \mathrm{Ni} 6 \mathrm{Mn} 9 \mathrm{~N}$ stainless steel tube in NC bending. It is found that the wrinkling wave ratio increases with the increasing of the bending angle, and the variation tendency slows down. This is because that the larger the bending angle, the more difficult the deformation. Thus, the wrinkling tendency increases with the increasing of the bending angle.

\subsection{Effect of relative bending radius on wrinkling.}

Retain $D=15.88 \mathrm{~mm}$ unchanged, change $R$, and select $R / D=\{2.0,2.5,3.0,4.0,5.0\}$. Fig.4(b) shows the effect of relative bending radius on wrinkling wave ratio of the $0 \mathrm{Cr} 21 \mathrm{Ni} 6 \mathrm{Mn} 9 \mathrm{~N}$ stainless steel tube in $\mathrm{NC}$ bending. It is can be see that the wrinkling wave ratio decreases with the increasing of the relative bending radius. It is because that with the decreasing of the relative bending radius, the deformation degree of the bent tube and the tangential compression stress of the intrados increase, which lead to the wall thickness of the intrados of bent tube increase. Thus, the wrinkling tendency increases with the decreasing of the relative bending radius.

\subsection{Effect of relative tube diameter on wrinkling.}

Retain $t=0.84 \mathrm{~mm}$ unchanged, change $D$, and select $D / t=\{16.0,18.9,22.0,25.0\}$. Fig.4(c) shows the effect of relative tube diameter on wrinkling wave ratio of the $0 \mathrm{Cr} 21 \mathrm{Ni} 6 \mathrm{Mn} 9 \mathrm{~N}$ stainless steel tube in $\mathrm{NC}$ bending. As can be seen from that the wrinkling wave ratio increases with the increasing of the relative tube diameter. This is because that the wall thickness and tangential compression stress of the intrados increase with the increasing of the relative tube diameter as shown in Fig.5, which cause the wrinkling tendency to increase.
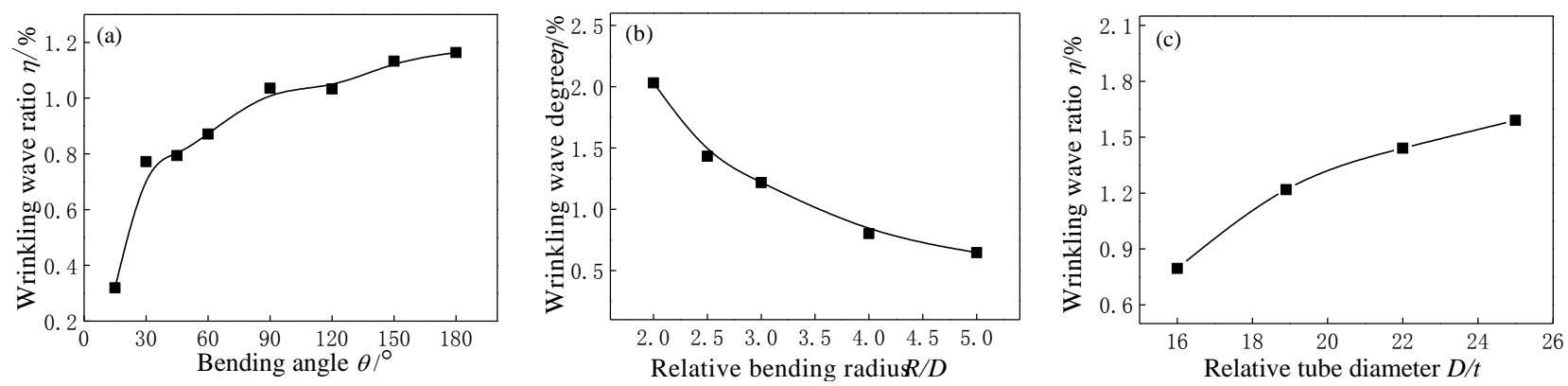

Fig.4 Effect of geometrical parameters on wrinkling of the $0 \mathrm{Cr} 21 \mathrm{Ni} 6 \mathrm{Mn} 9 \mathrm{~N}$ tube NC bending

(a) Bending angle $\theta$; (b) relative bending radius $R / D$; (c) relative tube diameter $D / t$
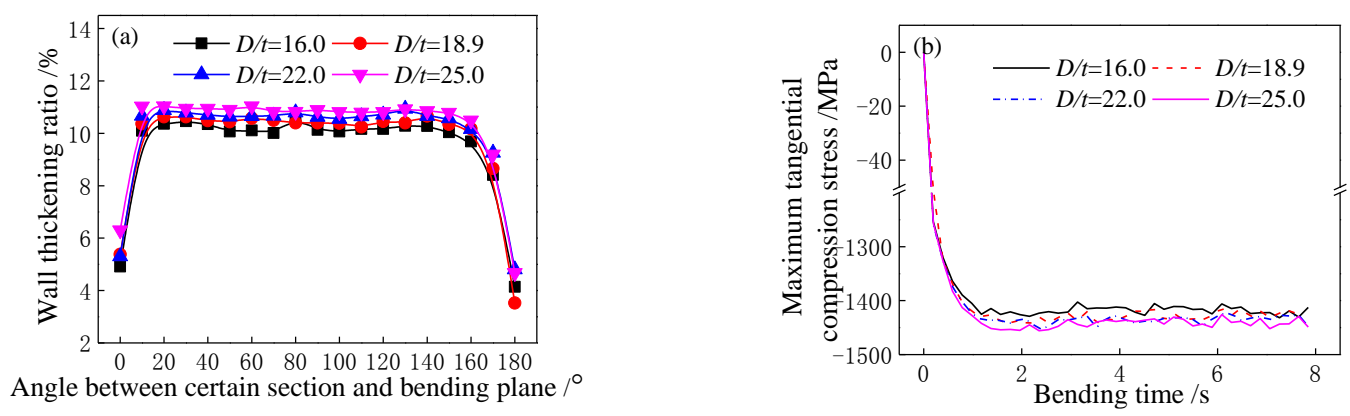

Fig. 5 Effect of $D / t$ on wall thickening ratio (a) and maximum tangential compression stress (b) of the $0 \mathrm{Cr} 21 \mathrm{Ni6Mn} 9 \mathrm{~N}$ tube $\mathrm{NC}$ bending 


\section{Conclusion}

(1) A 3D elastic plastic FE model of the $0 \mathrm{Cr} 21 \mathrm{Ni} 6 \mathrm{Mn} 9 \mathrm{~N}$ stainless steel tube in $\mathrm{NC}$ bending is established based on ABAQUS/Explicit code, and its reliability is validated by experiment.

(2) The wrinkling wave ratio increases with the increasing of the bending angle, and the variation tendency slows down.

(3) The wrinkling wave ratio increases with the increasing of the relative tube diameter or decreasing of the relative bending radius.

\section{Acknowledgements}

The authors would like to thank Key Project of Natural Science Research of Jiangxi Science \& Technology Normal University (No.2013XJZD001) for the support given to this research.

\section{References}

[1] Y.H. Wang, Z.Y Ma, J.L. Cao. 0Cr21Ni6Mn9N high temperature resistance stainless steel and its application in ramjet. J. Propul. Technol..Vol. 6 (1985), p.80-87.

[2] H. Yang, H. Li, Z.Y. Zhang, et al. Advances and trends on tube bending forming technologies. Chinese J. Aeronaut.. Vol.25 (2012) No.1, p.1-12.

[3] G.Y. Zhao, Y.L. Liu, C.S. Dong, et al. Analysis of wrinkling limit of rotary-draw bending process for thin-walled rectangular tube. J. Mater. Process. Technol.. Vol. 210 (2010) No.9, p.1224-1231.

[4] R. Peek. Wrinkling of tubes in bending from finite strain three dimensional continuum theory. Int. J. Solids Struct.. Vol.39 (2002) No.3, p.709-723.

[5] E. Corona, L.H. Lee, S. Kyriakides. Yield anisotropy effects on buckling of circular tube under bending. Int. J. Solids Struct.. Vol.43 (2006) No.22-23, p.7099-7118.

[6] J.S. Chen, D.X.E, J.W. Zhang. Effects of process parameters on wrinkling of thin-walled circular tube under rotary draw bending. Int. J. Adv. Manuf. Technol.. Vol.68 (2013) No.5-8, p.1505-1516.

[7] J. Fang, S.Q. Lu, K.L. Wang, et al. Deformation behaviors of 21-6-9 stainless steel tube numerical control bending under different friction conditions. J. Cent. South Univ.. Vol.22 (2015) No.8, p.2864-2874.

[8] H. Li, H. Yang, M. Zhan. A study on plastic wrinkling in thin-walled tube bending via an energy-based wrinkling prediction model. Modelling Simul. Mater. Sci. Eng.. Vol.17 (2009) No.3, p.1-33.

[9] J. Fang, S.Q. Lu, K.L. Wang, et al. Three-dimensional finite element model of high strength 21-6-9 stainless steel tube in rotary draw bending and its application. Indian J. Eng. Mater. Sci.. Vol.22 (2015) No.2, p.141-152. 